\title{
Study of Problems of Population's Poverty of Russia
}

\section{E. Fakhrutdinova}

E. Karasik

\section{J. Kolesnikova}

\section{R. Yagudin}

Kazan (Volga region) Federal University, 18, Kremlyovskaya Street, Kazan, Repablic of Tatarstan, Russian Federation, 420008

\section{Doi:10.5901/mjss.2014.v5n18p139}

\begin{abstract}
The main tendencies of poverty in Russia are considered in the article. It is defined that the main tendency of development of Russian economy for the last years is growth of poverty among the working population that generates a system of selfreproduction of poverty.
\end{abstract}

Keywords: poverty, abject poverty, evaluation criteria, poverty line, quality of life, poverty self-reproduction

\section{Specific Features of Research of Problems of Poverty}

The problem of poverty, abject poverty, definition of its criteria and borders are so actual that it is possible to say that many other problems are reduced to it. Questions of a demography, employment of population, unemployment; health of the population, education level and culture of citizens, their mannerliness, socialization and moral are directly connected with poverty. Poverty promotes a dehumanization of the human relations, rise in crime and terrorism, contributes to a fall of level and quality of life, decreases the economic security of the country as a whole and slows down development of civil society in Russia.

Special attention to a problem of poverty in Russia is caused, first of all, by the sharp growth of an inequality and of scales of expansion of poverty, considerable decrease in level and quality of life of the population during the period of reforming. It is anxious that poverty extends on the working population, youth which have to ensure the reproduction of population. Poverty is the reason of weakening of national security of the country, degradation of the population, complication of a demographic situation, strengthening of social contradictions in society [2], [10].

According to Zolotov A.V. [3] poverty is the social and economic phenomenon, which is unfortunately widespread in the modern world, including in Russia. Most often poverty is defined as lack funds, which are necessary for a normal life. Though this definition is correct, but, in his opinion, it isn't comprehensive enough. Poverty appears as a denial of welfare. Legitimacy of this representation isn't disproved by contrast of poverty and wealth. The matter is that in the modern society along with noted two poles the layer of financially secure people who can't be related neither to poor, nor to rich - "middle class" is widely presented. Though high welfare is a characteristic of middle class, this level doesn't correspond to the accepted ideas of wealth. Consequently poverty directly borders on welfare, instead of on wealth. Welfare in the modern economy with innovative character can be characterized as a complex of prerequisites for the free development of all society members. It is a question of a complex of prerequisites as reasonable needs of the person are diverse and in the same time are in unity. Free development can't be provided only with consumption of goods. Work with rich content and conducted under favorable for the person conditions is also necessary for the free development. Existence of free time, as time, which can be directly used for free development is required. If poverty is defined by welfare, welfare in itself doesn't assume contrast to poverty.

We agree with Zolotov A.V. [3] that consideration of poverty as denials of welfare allows to form the principle of classification of forms of poverty and to offer a system of forms of poverty corresponding to this principle. The essence of the presented approach is that a form of poverty is defined by denial of any element of welfare, either of their combinations, or of all together. On the basis of this postulate.

For a number of scientists [6], [7] problem of exarticulation of poor strata of society can be confined to an 
identification and description of quantitative indicators (which reflect a material structure of consumption of poor strata) corresponding to the low income and consumption level in the conditions of the available offer of goods and services and price level. Besides the concept poverty in social practice exists a concept of abject poverty. Proceeding from the standard norms, the state which lower than poverty level but which allows to remain within biologically admissible norms is called as abject poverty. The main characteristic of abject poverty can be expressed by the phrase "to drag miserable existence".

We totally agree with the opinion of Bagautdinova N. G. [9], [10] that in the world practice study of problems of an assessment of poverty and problems of definition of its criteria and borders is conducted constantly. Thus, the main efforts at studying a problem of poverty both in national and in global aspect are directed to give the universal or standardized determination of poverty. Economists developed the tradition of study in which the main indicator of poverty is distribution of income. In medicine the most powerful tool when studying poverty is the mortality indicator, which in the beginning was used for the analysis of health of population, but was gradually transformed to a poverty exponent. Another tradition of study develops on the basis of use of social indicators of human opportunities as a broader tool in understanding of poverty. One of recent researches within this tradition - calculation of an indicator of a standard of living which consists of the national income and two social indicators - literacy among adult population and probabilistic expectations of life expectancy. There is also other method of measuring of poverty. Poverty is measured by a number of hours, which are spent by the person to earn money for purchase of certain goods in different countries and at different types of occupations. Common thing for all these approaches is the search of the measuring tool, which would allow to compare poverty in different places and (or) in different time points. The most exact and the most used, though not quite adequate tools, in her opinion, are the analysis of distribution of the income and mortality indicators. Their main shortcoming - impossibility to measure all the aspects of poverty [9].

\section{Assessment of Poverty in the World}

Proceeding from criteria of the IMF, the UN and group of the World Bank criterion for definition of absolute level of poverty is the average daily income in the size of 1,25 dollars at par purchasing power. Exactly this sum for the last years is the average level of border of poverty and abject poverty in 15 of the most underdeveloped and economically backward countries of the world [6]. At the same time an alternative method of an assessment of a threshold of poverty and abject poverty is the average daily income of the population of 2 US dollars at par purchasing power. According to estimates of the IMF and the WB which try to embellish a situation with raising poverty in the world and to make amends of global monopolies in a lumpenization of overwhelming part of the population of a planet at the expense of artificial understating of maximum permissible size of the minimum income, in the recent years a rough median estimates of poverty in all developing countries of the world is 2 dollars. According to World Bank (WB) data, the share of the Russian citizens living less than for 2 dollars per day, was really reduced from 6\% in 2001 to less than 0,05\% following in 2009.

According to some scientists [2], [8] from 7 billion people on Earth, 2,5 billion live less than for 2 dollars a day that is threshold level of poverty by UN definition. Chronic shortage of drinking water is tested by 2,6 billion people. However children become the most vulnerable victims of poverty. Daily on a planet of hunger, diseases and deprivations die more than 30000 children and teenagers. To estimate the scale and a profile of planetary poverty not easy as there are some systems of estimates of this social phenomenon. Nevertheless, if to use criteria of the UN, it is possible to define the countries with prevailing number of citizens, whose consumption level or the income below the poverty line. The highest absolute poverty according to the UN, proceeding from the established national border, is observed on Madagascar $71 \%$ of citizens, Sierra Leone $-70 \%$, Mozambique $-69 \%$. If a to take a level of poverty 1 dollar a day (such indicator uses the UN for developing countries), the highest poverty is noted in Nigeria $(70,8 \%)$, the CAR $(66,6 \%)$ and Zambia $(63,8 \%)$. However a poverty line behind which poverty begins, - is a relative concept, in many respects depending on standards of consumption and the standard of living accepted in various regions of the world. In the USA the number of the poor is more than 46 million people. But as a poverty line of Bureau of population census of the USA considers the income equal to 22314 dollars a year on a family from four people (about 14 thousand Russian rubles per person a month). By criteria of the European Union, the poor person with the monthly income is considered less than 940 euros (about 37 thousand Russian rubles). By these calculations, today in Germany almost seventh part of the population, 11,5 million Germans, - live near the poverty line or already below it, and the number it over the last ten years increased by a third.. However, it is statistics of the global poverty expressed in figures. Definition of the reasons of extreme poverty is more difficult. Here is even more mosaic picture. If the African poverty is caused historically, and relative American or European poverty has first of all economic justifications, the poverty reasons in modern Russia - political mainly [2]. 


\section{Poverty in Russia}

We consider that now in economy of Russia there is a factor of self-reproduction of the poverty, caused by low level of the income, namely a salary. The underestimated level of a salary undermines reproduction of a manpower, is the powerful limiter of labor motivation and increase in purchasing power of the population and increase in production. The salary is the main source of the income of Russian inhabitants and made $64,6 \%$ of the monetary income of the Russian population in 2010. Dynamics of structure change of the population monetary income of the Russian Federation is characterized by the steady growth of the income from compensation during the period from 2005 to 2008 and decrease in 2009-2011 (tab. 1).

Table 1.The monetary income structure of the population of the Russian Federation (as a percentage to a result) [1]

\begin{tabular}{|l|c|c|c|c|c|c|c|c|}
\hline & 2005 & 2006 & 2007 & 2008 & 2009 & 2010 & 2011 \\
\hline \multicolumn{7}{|l|}{ As a percentage to a result } \\
\hline Monetary income, all & 100 & 100 & 100 & 100 & 100 & 100 & 100 \\
\hline Including: & \multicolumn{7}{|l|}{} & \multicolumn{5}{|c|}{10} \\
\hline Income from business activity & 11,4 & 11,1 & 10 & 10,2 & 9,5 & 8,8 & 8,9 \\
\hline Compensation * & 63,6 & 65,0 & 67,5 & 68,4 & 67,3 & 65,2 & 65,6 \\
\hline Social payments & 12,7 & 12,0 & 11,6 & 13,2 & 14,8 & 17,7 & 18,3 \\
\hline Income from property & 10,3 & 10,0 & 8,9 & 6,2 & 6,4 & 6,2 & 5,2 \\
\hline Other income & 2,0 & 1,9 & 2,0 & 2,0 & 2,0 & 2,0 & 2,0 \\
\hline
\end{tabular}

*- Including the hidden (unaccounted) salary

Thus at the poor there is a special subculture of the poverty, being characterized by existence of a vicious circle of poverty, "hereditary poverty" (children of the poor working population of the country) and absence of desire to work (tab. 2).

Table 2. Poverty reproduction 2009-2011yy[1]

\begin{tabular}{|l|c|c|c|}
\hline & 2009 & 2010 & \\
\hline Desire to work & $15,8 \%$ & $14,9 \%$ & $13,8 \%$ \\
\hline Non-desire to work & $6,3 \%$ & $7,1 \%$ & $9,1 \%$ \\
\hline
\end{tabular}

We agree with opinion of scientists (Zolotov A.V. Bagautdinova N. G., etc.) [2] [3], [7] that the share of poor as a part of country people in 1997-2002 was about 1,5 times higher, than among urban population. Data of Federal State Statistics Service prove that there is a differentiation in the income between peasants and city dwellers in Russia. Since 2004, level of poverty was reduced by only $38 \%$ in the cities, and in collective farms for only $20 \%$. In 2012 in rural areas already lived over $40 \%$ of the population relating to category of the needy population. Since 2002 poverty of the population living in rural areas increased from 33,8\% in 2002 to $40,4 \%$ in 2012 [1] all above allows to draw a conclusion that accommodation in rural areas is one of the strongest and steady risk factors of hit in group poor. The most part of the poor population of Russia is concentrated in rural areas. The difficult situation is also the small cities of regions of the country as they generally are economically dependent on the large cities.

One more of the reasons of poverty of Russians - backwardness of small business. So, only six small enterprises are the share of one thousand Russians, whereas in EU Member States - not less than thirty on the average. Only Moscow and St. Petersburg on the volume of distribution are close to level of Western Europe. About twenty small business enterprises are the share of one thousand their inhabitants [2], [6]. Thus according to official statistics [1] number of actually acting individual entrepreneurs across the Russian Federation increased from 1914,3 thousand people in 2010 to 2628,9 thousand people in 2012. In Russia in 2011 the share of SE in total number of the enterprises makes $29 \%$. In EU countries only the microenterprises make more than $90 \%$ of total number of the enterprises. Share of the Russian MT in employment - only $10 \%$ of total number working. In EU countries with this indicator for SME sector (small and medium-sized enterprises) - about 65\%. (see tab. 3). 
Table 3. Number of small enterprises and the businessmen in them in the world (2011) [1].

\begin{tabular}{|l|c|c|c|c|c|}
\hline Countries & $\begin{array}{c}\text { The quantity of } \\
\text { SME (thousand) }\end{array}$ & $\begin{array}{c}\text { SME Quantity on } \\
1000 \text { inhabitants }\end{array}$ & $\begin{array}{c}\text { occupied in SME } \\
\text { (million people) }\end{array}$ & $\begin{array}{c}\text { the Share of SME in the total } \\
\text { number of busy (\%) }\end{array}$ & $\begin{array}{c}\text { the Share of SME in gross } \\
\text { domestic product (\%) }\end{array}$ \\
\hline Great Britain & 2630 & 46 & 13.6 & 49 & $50-53$ \\
\hline Germany & 2290 & 37 & 18.5 & 46 & $50-52$ \\
\hline Italy & 3920 & 68 & 16.8 & 73 & $57-60$ \\
\hline France & 1980 & 35 & 15.2 & 54 & $55-62$ \\
\hline EU countries & 15770 & 45 & 68 & 72 & $53-67$ \\
\hline USA & 19300 & 74.2 & 70.2 & 78 & $52-52$ \\
\hline Japan & 6450 & 49.6 & 39.5 & 13 & $10-11$ \\
\hline Russia & 844 & 5.65 & 8.3 & & \\
\hline
\end{tabular}

The share of Russians with the income below a living wage made in $201211,0 \%$ against 1,0\% in 2009 from the total number of the population of the country. For comparison in the Republic of Tatarstan - in 2009 of $8,3 \%$ of the population with the income below a living wage, in $2012-6,7 \%$.

\section{Solutions of a Problem of Poverty}

In our opinion, small and medium business is the way of overcoming of poverty as new workplaces are created, the motivation to population work increases. Despite economy growth in Russia, all the same, in the country considerable differentiation of the population according to the income still keeps, there is a low wage of workers, therefore, high level of poverty remains [11]. According to official figures federal service of statistics of the Russian Federation [1], in 2011, the income of the most provided $10 \%$ of citizens exceeds the income of $10 \%$ of the least provided honor by 16,2 times, and in 2012 already by 16,4 times.

Distinctive feature of development of economy of the Russian Federation is that at us poverty of able-bodied population prevails. Without speaking about large and incomplete families with children, families with dependents, lonely pensioners, disabled people. The most terrible that efficient citizens aren't able to afford full-fledged due welfare because of low level of compensation or salary delays. Thus the reasons inducing economic poverty are that that independent acquisition of work by able-bodied population can't be a welfare source $[4,5]$.

We consider that poverty should be estimated not only on level of the income, but also on the consumption level reflecting quality of life. In our opinion, the part of the population gaining income from work belongs to the working poor, not allowing to satisfy natural and physiological, material and spiritual needs, both the working person, and members of his family and interfering labor reproduction. In our opinion, feature of the Russian poverty is that families working make more than $50 \%$ of the total number of the poor. Poverty of such families is caused by a high share of workers with a salary below a living wage and an unemployment of able-bodied members of households. Among $10 \%$ of the poorest workers of agriculture, wholesale and retail trade, education, health care and housing and communal services are most presented. Economic poverty is a poverty of the working population which level of compensation doesn't allow it to provide a worthy standard of living in present conditions. In fig. 1. consequences of poverty of the working population are presented.

\begin{tabular}{|c|c|c|}
\hline \multicolumn{3}{|c|}{ Consequences of poverty of the working population } \\
\hline $\begin{array}{l}\text { For the individual } \\
\text { - Negative attitude to the } \\
\text { Government and authorities, } \\
\text { and also to highly profitable } \\
\text { segments of the population } \\
\text { - Uncertainty in tomorrow } \\
\text { - Disappointmentin work } \\
\text { - Feeling of not demand } \\
\text { - Lack of opportunities and } \\
\text { desire to increase } \\
\text { qualification and an education } \\
\text { level }\end{array}$ & $\begin{array}{l}\text { For society } \\
\text { - Negative public } \\
\text { response } \\
\text { - Degradation } \\
\text { - Birth rate reduction } \\
\text { - Poverty reproduction }\end{array}$ & $\begin{array}{l}\text { For the state } \\
\text { - Politically passive population } \\
\text { - Economy inactive population } \\
\text { - Decrease in a skill level of } \\
\text { labor } \\
\text { - Decrease in quality of products } \\
\text { - Delay of scientific and } \\
\text { technical progress } \\
\text { - Decrease in quality of } \\
\text { education and education level } \\
\text { - Migration of the progressive } \\
\text { population to the developed } \\
\text { countries }\end{array}$ \\
\hline
\end{tabular}

Fig. 1. Indicator of consequences of poverty of the working population. 
The problem situation which has developed on a labor market, that the main source of the income for the majority of Russians the salary makes, and it, according to official figures Federal service of statistics the lowest, it is quite natural that had dominating impact on scales of distribution of poverty during economic transformations. Emergence of category of the working poor or "new poor", is connected, first of all, with low competitive positions of a domestic production.

For fight against poverty of the working population we offered the following measures: labor market regulation; development of territorial migration; creation of conditions for legalization of the income of the population; support of the poorest socially vulnerable segments of the population for providing conditions for realization of labor potential of part of the poor population having an active living position, being expressed in desire to work, abilities to study; increase of prestige of nonintellectual types of work; ensuring availability of mortgage lending; maintaining programs of support of small business; growth of middle class; improvement of quality of medical care.

Feature of a problem of poverty consists that it can be in this or that look in any economic system. Its essence varies depending on the volume of the made product and the saved-up wealth, including production potential or ways of distribution of material benefits and the income. Poverty and poverty became one of the critical factors excluding people from system of institutional interactions, reducing social space in which their relations, breaking their social identity were under construction. It reduces adaptation opportunities of a certain part of society to new economic conditions of development of social and economic systems. Complication of a problem of poverty and poverty in modern society happened and due to penetration of the related relations into many spheres of life. It is known that negative consequences of poverty and poverty are shown not only at personal level of the poor or poor person, but also at the level of interpersonal social interactions, and as all social and economic system.

\section{References}

Federal State Statistics Service. Electronic resource. Mode of access www.gks.ru free.

Fakhrutdinova, E. Safina, L. Kolesnikova, J. Mikhailov, F. 2013 . Quality formation of working life of the youth//World Applied Sciences Journal. Volume 27, Issue 13, ss. 87-91.

Zolotov A.V. Poverty as welfare denial: some conceptual and practical aspects//Modern art of economy. 2011 . No. 2 (2). Page 6-8.Tom Maclnnes, Hannah Aldridge, Sabrina Bushe, Peter Kenway and Adam Tinson Monitoring poverty and social exclusion 2013 http://www.jrf.org.uk/publications/monitoring-poverty-and-social-exclusion-2013 Hannah Aldridge, Peter Kenway, Tom Maclnnes and Anushree Parekh Monitoring poverty and social exclusion 2012 http://www.jrf.org.uk/publications/monitoring-poverty-2012

M.R., Elstin, L.A., Shakirova, A.I. 2012. Evaluation of business and economic activity as a short-term forecasting tool // Herald of the Russian Acad-emy of Sciences (4), pp. 290-294.

Bagautdinova, N.G., Eshugova, S.K., Saipullaev, U., Karasik, E.A. 2013. Methods of technology commercialization in projects of the agrofood system (AFS) development// World Applied Sciences Journal.Volume 27, Issue 13, pp. 48-52.

Gainova R.A., Shaidullin R.N., Safiullin L.N. and Maratkanova E.M. Infrastructural Component in Maintenance of Competitiveness of Region// World Applied Sciences Journal, 27(13), 2013, pp. 97-101.

Safiullin M.R., Samigullin I.G. and Safiullin L.N. Model of Management of Competitiveness of a Machine-building Complex// World Applied Sciences Journal, 27(13), 2013, pp. 212-216.

Glebova I.S., Sadyrtdinov R. and Rodnyansky D. Impact Analysis of Investment Attractiveness of the Republic of Tatarstan on Fixed Investments of its Leading Companies // World Applied Sciences Journal 26 (7): 911-916, 2013.

Bagautdinova, N.G., Novenkova, A.Z., Sarkin, A.V. 2013. Quality Management System Formulation and Implementation as a Factor of Enhancement of the university Role in the Local Development// World Applied Sciences Journal 27 (Economics, Management and Finance), pp. 38-42.

Fakhrutdinova,E.V., Fakhrutdinova, A.V., Severyanov, O.I., Valeev, E.R. 2013. The Transformation of Educational Approaches at the Time of Social and Economical Changes// World Applied Sciences Journal 27 (Economics, Management and Finance), pp. 1519.

Bagautdinova, N.G., Panasyuk, M.V., Gafurov, I.R. 2013. Wavelet Analysis of the Territorial Socio-Economic System Dynamics// World Applied Sciences Journal 27 (Economics, Management and Finance), pp. 62-66. 
